\title{
KONSTRUKSI KEARIFAN LOKAL MASYARAKAT PETANI HUTAN RAKYAT DALAM PEMANFAATAN DUWET (Syzygium cumini Linn)
}

\author{
(Construction of Local Wisdom of the Community Forest Farmers in the Utilization of Duwet \\ (Syzygium cumini Linn))
}

\author{
Maria Palmolina \& Eva Fauziyah \\ Balai Penelitian dan Pengembangan Teknologi Agroforestry \\ Jl. Raya Ciamis-Banjar Km.4 Ciamis 46201, Indonesia \\ E-mail: mariapalmolina@yahoo.com; fauziyah_eva@yahoo.com
}

Diterima 10 Februari 2017, direvisi 19 Oktober 2017, disetujui 5 Januari 2018

\begin{abstract}
One of the forms of ethnoecological tradition performed for generations by the people of the Triwidadi Village, Pajangan, DI Yogyakarta is the utilization of forest resources "duwet" (Syzygium cumini Linn) as a medicinal plant. However, these values and local wisdom received less recognition and appreciation from the government, especially to be considered as a basis in the formulation of forest management policies in Java. The aims of the study are to construct local wisdom in the utilization of duwet as a form of physical culture of an institutionalized knowledge system.by using cognitive ethnographic method. This semi-quantitative research is focused to seek sociological explanation of cultural knowledge systems and duwet utilization process. Duwet habitat is in natural forest, secondary forest, and garden-yard, describes the form of changes in the environmental adaptation and social processes of forest resource utilization. The results showed that there is a symbolic interaction in the utilization of duwet consisting of constitution, cognitive, assessment and disclosure feeling symbols. In the construction of local knowledge, the utilization of duwet reflects six essential elements of ethnoecology, namely local resources, local knowledge, local value, local skills, local solidarity groups, and mechanisms of local decision-making.
\end{abstract}

Keywords: Duwet; Syzygium cumini Linn; local knowledge; symbolic interaction.

\begin{abstract}
ABSTRAK
Salah satu wujud etnoekologi yang dianut secara turun temurun oleh masyarakat Desa Triwidadi, Pajangan, DI Yogyakarta adalah pemanfaatan sumber daya hutan jenis tanaman obat "duwet" (Syzygium cumini Linn). Permasalahannya adalah bahwa nilai dan bentuk kearifan lokal tersebut kurang mendapat pengakuan dan penghargaan dari pemerintah, apalagi digunakan sebagai salah satu dasar pertimbangan dalam penyusunan kebijakan pengelolaan hutan di Jawa. Sebagai penelitian awal, kajian ekologi-budaya ini bertujuan mengkonstruksikan kearifan lokal pemanfaatan duwet sebagai salah satu wujud kebudayaan fisik dari sistem pengetahuan yang bersifat melembaga. Penelitian kualitatif semi kuantitatif ini menggunakan metoda etnografi kognitif dalam mencari penjelasan sosiologis dari sistem pengetahuan budaya dan proses pemanfaatan duwet. Habitat tanaman duwet pada hutan alam, hutan sekunder, dan kebun-pekarangan menggambarkan bentuk perubahan adaptasi lingkungan dan proses sosial dari pemanfaatan sumber daya hutan. Hasil penelitian menunjukkan bahwa terdapat interaksi simbolik dari pemanfaatan duwet antara lain berupa simbol konstitusi, simbol kognitif, simbol penilaian, dan simbol pengungkapan perasaan. Dalam konstruksi kearifan lokal proses pemanfaatan duwet ditemukan enam unsur penting etnoekologi yaitu sebagai sumber daya lokal, pengetahuan lokal, nilai lokal, keterampilan lokal, solidaritas kelompok lokal, serta mekanisme pengambilan keputusan lokal.
\end{abstract}

Kata kunci: Duwet; Syzygium cumini Linn; kearifan lokal; interaksi simbolis. 


\section{PENDAHULUAN}

Semenjak penciptaan manusia di muka bumi ini, manusia hidup berdampingan dan beradaptasi dengan lingkungan alamnya. Secara umum masyarakat Indonesia lebih akrab dengan lingkungan alaminya daripada lingkungan teknologinya. Masyarakat petani Desa Triwidadi merupakan salah satu masyarakat yang secara administratif berada di Kecamatan Pajangan Kabupaten Bantul Provinsi Daerah Istimewa (DI) Yogyakarta. Secara tradisional masyarakat petani hutan rakyat di Desa Triwidadi memanfaatkan tanaman hutan jenis obat Syzygium cumini Linn, yang secara lokal dikenal dengan nama "Duwet". Syzygium cumini Linn adalah tergolong tumbuhan buah-buahan yang berasal dari Asia dan Australia Tropik (Balitbang Pertanian, 2015). Nama lain Syzygium cumini Linn (Family Myrtaceae) adalah duwet, juwet, jamblang, jembe, jambolan, blackplum, java pulm, indian blackberry, jamun dan lain-lain. Persebaran dengan keanekaragaman tinggi terdapat dari Malaysia sampai timur laut Australia. Kini tanaman ini telah tumbuh di beberapa bagian benua Asia, Afrika Timur, Amerika Selatan, Madagaskar dan telah secara alami tumbuh di Florida dan Hawai di USA (Ayyanar \& Subash-Babu, 2012). Secara garis besar varietas jamblang ada tiga yaitu duwet krikil, duwet bawang/putih dan duwet hitam (Heyne, 1987 dalam Palmolina and Sudomo, 2015).

Biji duwet merupakan bagian utama yang bermanfaat sebagai obat. Ekstrak biji duwet berfungsi sebagai obat diabetes, hypoglycemic, antiinflamnatory, antioxidant, dan kemoprefentif terhadap stres dan kerusakan genom (Prince \& Venon, 1998). Ekstrak buah ini menghasilkan antioksidan dan antikanker tertinggi (Afify, Fayed, Shalaby, \& El-Shemy, 2011). Buah duwet juga dapat mengobati diabetes karena dapat menurunkan gula darah. Selain itu, biji duwet juga dapat digunakan untuk menunda komplikasi seperti saraf dan kataraks (Helmstädter, 2008).
Potensi untuk menggalakan kembali obatobatan dari herbal di Indonesia sangat terbuka lebar. Nilai perdagangan tanaman obat (herbal) pada tahun 2000 mencapai US\$40 miliar. Pada tahun 2002 meningkat menjadi US\$60 miliar dan tahun 2050 diperkirakan menjadi US\$5 triliun dengan peningkatan $15 \%$ per tahun, lebih tinggi jika dibandingkan dengan peningkatan nilai perdagangan obat konvensional modern yang hanya 3\% per tahun (Balitbang Pertanian, 2007). Sementara keberadaannya kini makin sulit ditemui, khususnya di Pulau Jawa, seperti Kabupaten Majalengka yang pada dekade 1970-an merupakan sentra tanaman duwet, namun kini telah dibabat habis menjadi komoditi tanaman perkebunan (Mulyana \& Sudomo, 2015). Sebaliknya di Kabupaten Bantul, khususnya Desa Triwidadi, tanaman duwet masih banyak tersebar di pekarangan dan kebun. Bahkan pemanfaatan tanaman duwet secara tradisional oleh masyarakat petani telah membentuk kearifan lokal yang merupakan salah satu simbol interaksi (interactionisme symbolic) manusia dan lingkungan alamnya. Permasalahannya ialah bahwa nilai dan bentuk kearifan lokal tersebut kurang mendapatkan pengakuan (recognition) dan penghargaan dari pemerintah. Akibatnya, selain model pengelolaan hutan yang diterapkan saat ini belum mampu mengakomodir kepentingan masyarakat lokal, kearifan lokal tersebut juga berangsur-angsur semakin dilupakan. Salah satu dampak lanjutan yang mengkhawatirkan adalah kelangkaan tanaman duwet di Indonesia.

Oleh karena itu, tujuan dari kajian ini adalah untuk (1) Memperoleh informasi tentang karakteristik sosial-budaya masyarakat petani hutan rakyat di Desa Triwidadi dalam pemanfaatan tanaman duwet sebagai sumber daya hutan lokal; (2) Mendokumentasikan bentuk simbolsimbol interaksi dalam proses pemanfaatan tanaman duwet; dan (3) Mengkonstruksikan bentuk kearifan lokal pemanfaatan tanaman 
duwet sebagai salah satu wujud kebudayaan fisik dari sistem pengetahuan (etnoekologi) yang bersifat melembaga. Hasil kajian ini diharapkan bermanfaat untuk menambah khazanah pengetahuan tentang karakter sosial-budaya komunitas suku Jawa sekaligus menjembatani diskursus dalam proses pemanfaatan sumber daya alam (SDA) yang adaptif dalam perumusan kebijakan pengelolaan hutan rakyat di pulau Jawa bagi terwujudnya pemanfaatan hutan rakyat yang berkelanjutan.

\section{METODE PENELITIAN}

\section{A. Lokasi, Waktu Penelitian dan Pengumpulan Data}

Berdasarkan hasil survey lokasi dan keterangan dari Sekretaris Kecamatan Pajangan, bahwa salah satu desa yang diketahui populasi tanaman duwetnya masih relatif banyak adalah Desa Triwidadi. Desa tersebut terletak di Kecamatan Pajangan, Kabupaten Bantul, Provinsi D.I. Yogyakarta. Penelitian dilakukan dari bulan Juni sampai bulan Oktober 2015. Penelitian ini difokuskan untuk mencari penjelasan sosiologis dari sistem pengetahuan budaya dan proses pemanfaatan tanaman duwet dengan menggunakan metode etnografi kognitif dalam pengumpulan data primer dan sekundernya.

Sumber data diperoleh secara wawancara langsung dari informasi masyarakat yang berada di lokasi penelitian dengan model "snowball", yaitu salah satu teknik untuk menemukan dan mengidentifikasi informan dan responden yang dimaksud sebagai sasaran penelitian, melalui keterkaitan suatu jaringan (Nurdiani, 2014). Responden dan informan memenuhi syarat utama sebagai pelaku yang terlibat dalam proses pemanfaatan tumbuhan duwet. Jumlah informan sebanyak tujuh orang yang diambil dari tokoh adat/agama, kepala desa, penyuluh, ketua kelompok tani, dan petani yang memiliki tanaman duwet dan mengetahui sejarah tanaman duwet, sementara jumlah responden sebanyak 35 orang yang diambil dari anggota kelompok tani. Proses konstruksi dialektika fenomena sosial sebagai model kajian ekologi-budaya didekati dengan metode etnografi yang dikembangkan oleh Spreadley (2006), melalui tahap pengamatan terlibat, wawancara, dan literatur untuk mengumpulkan data budaya tani masyarakat petani di Desa Triwidadi dan habitat tanaman duwet yang selanjutnya dijadikan sebagai serangkaian data etnoekologi.

\section{B. Data dan Metode Analisis Data}

Jenis data dan informasi yang dikumpulkan terdiri atas data etnografi dan data ekologi. Data etnografi masyarakat petani di Desa Triwidadi dan data ekologi tanaman duwet yang sudah terhimpun diklasifikasikan dan dideskripsikan secara holistik integratif melalui pendekatan interpretative research dan basic research, dianalisis dan ditafsirkan secara kualitatif dari sudut pandang konstruksi sosial Berger dari sistem pengetahuan budaya tentang pemanfaatan tanaman duwet.

Analisis data menggunakan metode deskriptif, yakni analisis data dengan menerapkan tiga alur, yaitu (1) Reduksi data; (2) Penyajian data; dan (3) Penarikan kesimpulan/verifikasi (Satory \& Komariah, 2009). Proses analisis data dimulai dengan menelaah seluruh data yang tersedia dari berbagai sumber, yaitu hasil wawancara, hasil observasi, dokumen, laporan, peraturan, gambar, foto, serta dokumen lainnya. Penafsiran data dilakukan secara etik maupun emik. Penafsiran data secara etik yaitu data ditafsirkan menurut pandangan peneliti, sedangkan secara emik yaitu data ditafsirkan menurut pandangan dari subyek penelitian itu sendiri dengan dukungan dari data primer (hasil survey) dan data sekunder (monografi desa, Badan Pusat Statistik/BPS kecamatan, dan lainnya) yang ada berdasarkan kajian teoritis yang relevan. Selanjutnya dianalisis berupa uraian. Uraian yang dimaksud lebih sebagai penjabaran secara deskriptif analitis. Analisis data kualitatif menurut Bogdan dan Steven (1993) dalam Palmolina (2013) 
adalah upaya yang dilakukan dengan jalan bekerja dengan data, mengorganisasikan data, memilah-milahnya menjadi satuan yang dapat dikelola, mensintesiskannya, mencari dan menemukan pola, menemukan apa yang penting dan apa yang dipelajari, dan memutuskan apa yang dapat diceritakan kepada orang lain.

Pengujian keabsahan data dalam penelitian ini menggunakan teknik triangulasi. Triangulasi dalam penelitian ini akan memanfaatkan penggunaan sumber yang dilakukan dengan membandingkan data hasil pengamatan dengan hasil wawancara, membandingkan yang dikatakan orang di depan umum dengan yang dikatakannya secara pribadi, dan membandingkan yang dikatakan orang-orang tentang situasi penelitian dengan yang dikatakan sepanjang waktu. Peneliti juga dapat membandingkan keadaan dan perspektif seseorang dengan berbagai pendapat dan pandangan orang di luar obyek kajian, dan membandingkan hasil wawancara dengan isi suatu dokumen yang berkaitan.Triangulasi juga dilakukan dengan menggunakan teori sebagai penjelasan pembanding atas fakta yang ada.

\section{HASIL DAN PEMBAHASAN}

\section{A. Karakteristik Ekologi Budaya Masyarakat Petani Desa Triwidadi}

Desa Triwidadi terbentuk sejak tahun 1946. Desa Triwidadi merupakan desa hasil merger dari tiga desa yaitu Desa Kersan, Desa Butoh, dan Desa Pajangan. Penyatuan dari tiga desa ini dinamakan Desa "Triwidadi", yang artinya "tiga desa menjadi satu". Kepemimpinan di Desa Triwidadi mengalami tiga periode (Tabel 1), yaitu (1) Bapak Arjo Agus Tomo pada tahun 1946-1987, (2) Bapak Mardiyono pada tahun 1987-2007, dan (3) Bapak Slamet Riyanto pada tahun 2007 hingga sekarang.

Tabel 1 Alur sejarah dan perubahan penggunaan lahan di Desa Triwidadi

Table 1 Chronology of the history and land use changes in Triwidadi Village

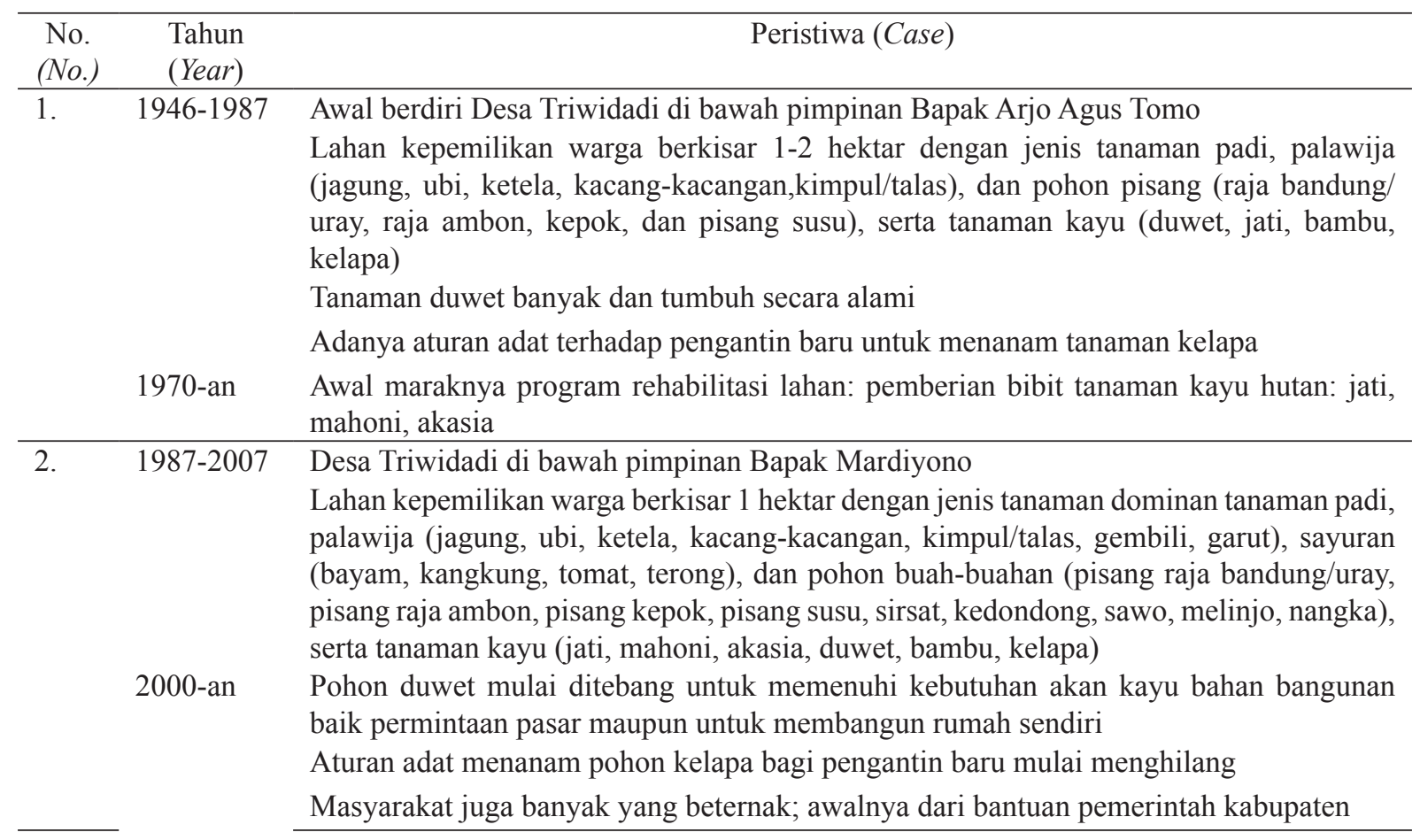




\begin{tabular}{|c|c|c|}
\hline $\begin{array}{l}\text { No. } \\
\text { (No.) }\end{array}$ & $\begin{array}{l}\text { Tahun } \\
\text { (Year) }\end{array}$ & Peristiwa (Case) \\
\hline \multirow[t]{5}{*}{3.} & 2007-an & Desa Triwidadi di bawah pimpinan Bapak Slamet Riyanto \\
\hline & s.d. 2015 & $\begin{array}{l}\text { Lahan kepemilikan warga berkisar } 0,2 \text { hektar dengan jenis tanaman dominan tanaman } \\
\text { padi/ palawija/sayuran dan beberapa tanaman buah-buahan dan kayu hutan }\end{array}$ \\
\hline & & $\begin{array}{l}\text { Pohon duwet semakin berkurang, diprediksi pohon duwet yang ada di Desa Triwidadi } \\
\text { tinggal } 60 \% \text { saja dan wilayah terbanyak berada di Dusun Jojoran Wetan }\end{array}$ \\
\hline & & $\begin{array}{l}\text { Aturan adat menanam kelapa bagi pengantin baru sudah hilang; tak ada yang menjalani } \\
\text { bahkan bagi generasi muda tidak pernah tahu ada aturan tersebut }\end{array}$ \\
\hline & 2015 & $\begin{array}{l}\text { Komoditas lahan selain yang telah ada (padi, palawija (jagung, ubi, ketela, kacang- } \\
\text { kacangan, kimpul/talas, gembili, garut), sayuran (bayam, kangkung, tomat, terong), dan } \\
\text { pohon buah-buahan (pisang raja bandung/uray, pisang raja ambon, pisang kepok, pisang } \\
\text { susu, sirsat, sawo, kedondong, melinjo, nangka), serta tanaman kayu (jati, mahoni, akasia, } \\
\text { duwet, bambu, kelapa) juga sedang digerakkan kembali penanaman bambu, garut, aren, } \\
\text { gayam, salam, kelengkeng, mangga gadung, dan jambu biji }\end{array}$ \\
\hline
\end{tabular}

Sumber (Source): Data primer (Primary data), 2015

Pada masa kepemimpinan Bapak Arjo dan Bapak Mardiyono, ada aturan yang mewajibkan pengantin baru untuk menanam pohon kelapa, namun hilang bersamaan dengan program rehabilitasi lahan pada sekitar tahun 1970-an; dengan banyaknya pemberian bibit, kewajiban menanam pohon kelapa perlahanlahan menghilang. Rata-rata lahan yang dimiliki oleh warga desa sempit, sehingga ketika diberi bibit tanaman hutan gratis, maka tak ada lagi sisa lahan untuk ditanami dengan pohon kelapa. Jenis pemberian bibit pada saat itu adalah tanaman jenis jati, mahoni, dan akasia. Pohon jati tumbuh alami dengan suburnya sampai dengan sekarang, bahkan akar-akarnya melebar memenuhi lahan milik sebagian besar masyarakat Desa Triwidadi. Dampaknya untuk menanam tanaman lain seperti tanaman buah-buahan diperlukan kerja keras untuk membersihkan akar-akar bekas jati yang tertanam dalam dan merambat luas di lahan petani.

Secara umum lahan basah maupun kering di Desa Triwidadi dikelola secara intensif dengan luasan kepemilikan lahan per-kepala keluarga (KK) kini berkisar 300 hingga 400 bata, dimana satu bata setara dengan $14 \mathrm{~m}^{2}$. Hasil pertanian dominan dikonsumsi sendiri, yang merupakan ciri dari pertanian subsisten. Bila dulu ada yang memiliki lahan sampai dengan $>1$ hektar, sekarang hampir tidak ada lagi karena telah dibagi-bagi kepada ahli warisnya. Rata-rata kepemilikan lahan garapan petani di Desa Triwidadi ini mayoritas berada di luasan $<0,25$ hektar (42\%). Lahan yang mereka miliki tersebut mayoritas merupakan warisan (66\%). Berdasarkan penelitian yang dilakukan oleh Susanto \& Sulasno (2014) bahwa hasil analisis kelayakan finansial pola agroforestri pada lahan seluas $<0,5$ hektar adalah layak dipakai. Melihat luasan kepemilikan lahan masyarakat petani berkisar $<0,25$ hektar (42\%) dan 0,25-0,5 hektar (28\%) di Desa Triwidadi, maka dapat dikatakan layak dilakukan pola agroforestri, dengan jenis tanaman yang bervariasi (Diniyati, Achmad, \& Santoso, 2013).

Karakter petani di Desa Triwidadi adalah semaksimal mungkin mereka mengelola lahan yang mereka miliki dengan berbagai macam tanaman (agroforestri). Tidak hanya tanaman pertanian, seperti padi, palawija, dan tanaman herbal/empon-empon, tetapi juga tanaman perkebunan dan kehutanan, seperti tanaman buah-buahan, kelapa, dan tanaman kayu hutan seperti jati, mahoni, akasia, albasia, dan lain-lain (Tabel 2). Hal ini selaras dengan penjelasan dari Utari (2010) bahwa dalam penerapan agroforestri pada lahan-lahan milik, petani mampu memilih, mengembangkan, dan mengatur komponenkomponen tanaman yang paling sesuai dan 
Tabel 2 Jenis penyusun hutan rakyat di Desa Triwidadi

Table 2 Type of comunity forest trees in Triwidadi Village

\begin{tabular}{|c|c|}
\hline Kategori (Category) & $\begin{array}{l}\text { Jenis penyusun hutan rakyat } \\
\text { (Component of private forest type) }\end{array}$ \\
\hline Kayu (Wood) & mahoni, jati, bambu, duwet, jabon, akasia, palem, karet \\
\hline $\begin{array}{l}\text { Hasil hutan bukan kayu } \\
\text { (HHBK) buah (Non } \\
\text { Timber Forest Product } \\
\text { (NTFP) fruit) }\end{array}$ & $\begin{array}{l}\text { nangka, kedondong, sawo, pisang, asem, sirsak, mices, jambu biji, lengkeng, } \\
\text { alpukat, kelapa }\end{array}$ \\
\hline \multirow[t]{3}{*}{ Tanaman bawah $(\mathrm{Herbs})$} & empon-empon/herbal: jahe, kunyit, laos, sereh, kemangi \\
\hline & $\begin{array}{l}\text { palawija: padi, cabe rawit, cabe merah, jagung hibrida, kecipir, bayam, kangkung, } \\
\text { kacang panjang, tomat, kacang bogor, terong, pare }\end{array}$ \\
\hline & umbi-umbian: talas, ubi kayu. \\
\hline Kolam (Ponds) & Lele \\
\hline Ternak (livestock) & ayam, kambing, mentok, sapi. \\
\hline
\end{tabular}

Sumber (Source): Data primer (Primary data), 2015

mampu bersinergi satu sama lain, sehingga dapat memberikan keuntungan yang optimal bagi kesejahteraan petani dan keluarganya. Hal yang sama disampaikan oleh Kusumedi and Jariyah (2010) bahwa agroforestri merupakan pilihan tepat dalam pemanfaatan lahan milik masyarakat/petani karena mampu memberikan pendapatan dalam jangka pendek untuk biaya hidup harian dan pendapatan jangka panjang sebagai tabungan.

\section{B. Interaksi Simbolis Tanaman Duwet}

Hubungan harmonis masyarakat dengan lahan kebun/hutan rakyat-nya telah menjadi kultur dan identitas suatu komunitas, bahkan sikap dan tindakan mereka merupakan cermin kebudayaan mereka. Proses perubahan lingkungan ekologi habitat tanaman duwet yang diawali dari tumbuhan liar menjadi tumbuhan yang dibudidayakan (kebun pekarangan/hutan rakyat) merupakan wujud respon adaptasi masyarakat petani hutan rakyat di Desa Triwidadi ini dalam memanfaatkan potensi sumber daya alamnya. Proses perubahan lingkungan di Desa Triwidadi ini sebagaimana dijelaskan kepala desa, telah berlangsung semenjak terbentuknya Desa Triwidadi. Berawal dari pembukaan lahan untuk pemukiman dan kebutuhan untuk memberi batas antar lahan warga desa, semenjak itu pula tanaman duwet mulai dibudidayakan, terutama di lahan miring.

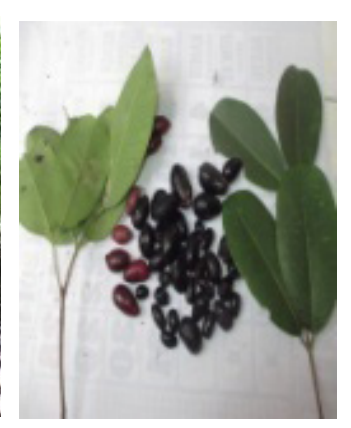

Sumber (Source): Data primer (Primary data), 2015

Gambar 1 Morfologi Syzigium cumini Linn

Figure 1 Morphology of Syzygium cumini Linn 
Tabel 3 Pengetahuan responden tentang tanaman duwet

Table 3 Respondents knowledge on duwet's plant

\begin{tabular}{|c|c|c|c|}
\hline No. & $\begin{array}{c}\text { Uraian } \\
(\text { Description }) \\
\end{array}$ & $\begin{array}{c}\text { Jumlah } \\
\text { (Number) }\end{array}$ & $\%$ \\
\hline \multirow[t]{3}{*}{1.} & Mengetahui jamblang/duwet (Do you find out what the Duwet is?) & & \\
\hline & 1. ya (Yes) & 35 & 100 \\
\hline & 2. tidak $(\mathrm{No})$ & 0 & 0 \\
\hline \multirow[t]{5}{*}{2.} & Sejak kapan mengetahuinya (Since when did you find out?) & & \\
\hline & 1. $<$ tahun $1980(<$ year 1980$)$ & 21 & 60 \\
\hline & 2. tahun $1980-1990$ (year $1980-1990$ ) & 8 & 23 \\
\hline & 3. tahun 1991-2000 (year 1991-2000) & 4 & 11 \\
\hline & 4. >tahun $2000($ year 2000) & 2 & 6 \\
\hline \multirow[t]{3}{*}{3.} & Anggota keluarga mengetahui semua (All family members know it) & & \\
\hline & 1. ya (Yes) & 34 & 97 \\
\hline & 2. sebagian, siapa saja (Some of them, who?) & 1 & 3 \\
\hline \multirow[t]{4}{*}{4.} & Budidaya tanaman jamblang/duwet (Cultivation of duwet plant) & & \\
\hline & 1. tumbuh secara alami (grow naturally) & 33 & 94 \\
\hline & 2. sengaja ditanam (planted intentionally) & 2 & 6 \\
\hline & 3. tidak tahu (do not know) & 0 & 0 \\
\hline \multirow[t]{4}{*}{5.} & $\begin{array}{l}\text { Keberadaan tanaman jamblang/duwet di sekitar wilayah desa (The } \\
\text { existence duwet plants around the village area) }\end{array}$ & & \\
\hline & 1. mulai langka (rare) & 25 & 71 \\
\hline & 2. masih banyak (abundance) & 9 & 26 \\
\hline & 3. tidak tahu (do not know) & 1 & 3 \\
\hline \multirow[t]{3}{*}{6.} & $\begin{array}{l}\text { Tanaman jamblang/duwet dijadikan alternatif pengobatan (Duwet } \\
\text { plant used as an alternative medicinal treatment) }\end{array}$ & & \\
\hline & 1. ya (Yes) & 8 & 23 \\
\hline & 2. tidak (No) & 27 & 77 \\
\hline
\end{tabular}

Sumber (Source): Data primer (Primary data), 2015

Berdasarkan bentuk morfologi buah duwet, buah merupakan bagian tanaman yang paling dominan dimanfaatkan oleh masyarakat Desa Triwidadi. Proses pemanfaatan buah duwet dimulai dari tahapan pra-panen, panen, dan pasca-panen. Selain buah, biomassa tegakan (kayu) juga dapat dimanfaatkan sebagai bahan bangunan dan kayu bakar (Gambar 1).

Tanaman buah duwet bagi masyarakat Desa Triwidadi bukanlah sesuatu yang aneh lagi. Semua responden mengenal betul tanaman tersebut. Bagi masyarakat Desa Triwidadi tanaman duwet merupakan makanan cemilan yang selalu mereka tunggu setiap tahunnya. Selain itu, tampilan fisik pohon duwet dijadikan simbol batas hak dan wilayah kepemilikan lahan keluarga, berdasarkan kepemilikan tegakan dan luas kekuasaan/ kepemilikan lahan.

Keberadaan tanaman duwet di Desa Triwidadi ini masih terbilang cukup banyak, sebab tanaman tersebut mudah tumbuh (tumbuh alami). Sekitar 94\% responden mengungkapkan bahwa sekalipun masyarakat tidak membudidayakan, tanaman duwet masih saja banyak karena tumbuh dengan sendirinya (alami) (Tabel 3). Selain itu, alasan mereka membiarkan tanaman duwet tumbuh dikarenakan mereka memang terbiasa dengan tanaman duwet, dan menikmati keberadaannya, serta diharapkan cepat besar, berbuah, dan menikmati buahnya. Hal ini 
sejalan dengan Berger and Lukhman (1990) dalam Ungirwalu and Awang (2011) yang menjelaskan mengenai konstruksi sosial; bahwa tanaman duwet telah mengalami proses eksternalisasi, obyektivasi, dan internalisasi sehingga menjadi bagian dalam kehidupan masyarakat petaninya.

Saat ini keberadaan tanaman duwet mulai langka. Hal ini dikarenakan penebangan tanaman duwet banyak dilakukan sejak awal tahun 2000. Beberapa alasan penebangan pohon duwet tersebut adalah (1) Pemenuhan kebutuhan hidup rumah tangga petaninya, dimana pada saat itu krisis moneter melanda di negara Indonesia, yang mengakibatkan perekonomian menurun tajam, sementara kebutuhan hidup harus terpenuhi; (2) Permintaan pasar akan kebutuhan kayu meningkat. Masyarakat melihat peluang itu, maka dalam upaya memenuhi kebutuhan rumah tangganya, mereka mulai menebang pohon yang mereka miliki dan menjualnya, termasuk pohon duwet. Masyarakat berpendapat bahwa secara ekonomi, tanaman duwet lebih bermanfaat bilamana dijual kayunya, daripada menjual buahnya (perhitungan biaya panen dengan hasil jual tidak sebanding). Terlebih ada penampung yang datang ke Desa Triwidadi yang selalu siap menerima penjualan kayu duwet (Tabel
4 dan 5). Salah satu alasan pohon duwet dijual, meski dari harganya masih relatif rendah adalah petani belum mengetahui manfaat tiap bagian pohon duwet. Sebagian besar responden $(71,4 \%)$ belum mengetahui kandungan dan manfaat dari keseluruhan tanaman duwet, meskipun mereka mengenal tanaman duwet sejak tahun 1970-an (60\%) (Tabel 3). Sebagian kecil dari masyarakat (8 orang) saja yang mengerti manfaat pengobatan dari tanaman duwet, yakni bagian kulitnya untuk pengobatan diare (Tabel 3); (3) Alasan menebang pohon duwet berikutnya adalah sebagai bahan bangunan untuk membangun rumah keluarga baru. Mereka berpendapat bahwa kayu duwet kuat karena telah berusia puluhan tahun dan memiliki tekstur serat yang indah sebagai pintu, jendela, dan kusen. Beberapa tahun terakhir kayu duwet dijadikan sebagai bahan furniture lemari, meja, kursi, dan lainnya (Tabel 4).

Dari berbagai alasan pohon duwet ditebang/dipanen tersebut, menyebabkan keberadaan duwet kini semakin berkurang di Desa Triwidadi; $71 \%$ dari responden menyatakan bahwa keberadaan tanaman duwet memang telah berkurang dan mulai langka keberadaannya (Tabel 3). Bahkan di Majalengka yang dulu disebut sebagai sentra tanaman duwet kini telah dibabat habis

Tabel 4 Pemanfaatan tanaman duwet

Table 4 Utilization of duwet's plant

\begin{tabular}{ll}
\hline $\begin{array}{c}\text { Bagian tanaman } \\
\text { (Part of plant) }\end{array}$ & \multicolumn{1}{c}{ Pemanfaatan (Utilization) } \\
\hline Buah (Fruit) & $\begin{array}{l}\text { Dimakan (sudah menjadi budaya; merasa ada yang kurang bila tak makan buah duwet } \\
\text { dalam sehari pada saat musim buah yang terjadi sekali dalam setahun selama satu-dua } \\
\text { bulan) }\end{array}$ \\
Biji (Seed) & - \\
$\begin{array}{l}\text { Daun (Leaf) } \\
\text { Kayu (batang, } \\
\text { dahan,ranting) (Wood }\end{array}$ & $\begin{array}{l}\text { Sebagai bahan bangunan, furniture karena serat kayu terlihat indah, rantingnya untuk } \\
\text { (Stems, Branches, }\end{array}$ \\
$\begin{array}{l}\text { Twigs) } \\
\text { Kulit (Tree Skin) }\end{array}$ & Untuk obakar diare \\
Akar (Root) & - \\
\hline
\end{tabular}

Sumber (Source): Data primer (Primary data), 2015 
Tabel 5. Pemasaran tanaman duwet

Table 5. Marketing of duwet's plant

\begin{tabular}{lll}
\hline Bagian yang dijual (Parts sold) & $\begin{array}{l}\text { Tempat jual } \\
\text { (Place to sell) }\end{array}$ & Harga (Price) \\
\hline Batang kayu dan buah & Bandar & Buah seharga Rp2.000,00 - Rp3.000,00 per kg \\
& & Batang/kayu seharga Rp400.000,00 hingga \\
& & Rp800.000,00 per batang dalam kondisi berdiri \\
\hline
\end{tabular}

Sumber (Source): Data primer (Primary data), 2015

diganti dengan tanaman perkebunan yang lebih komersil dibandingkan tanaman duwet (Balitbang Pertanian, 2007).

Kenyataan dan pengetahuan masyarakat petani di Desa Triwidadi, menjelaskan interaksi simbolis pemanfaatan tanaman duwet, bahwa hubungan interaksi yang terjadi antara masyarakat Desa Triwidadi dengan tanaman duwet dapat dilihat dalam dua dimensi, sebagaimana yang dijelaskan oleh Rudito dan Femiola dalam Ungirwalu and Awang (2011), yakni sistem budaya dan sistem sosial; hubungan interaksi yang terjadi antara individu dalam masyarakat Desa Triwidadi (sistem sosial) sebagai adaptasi dengan lingkungan dalam memanfaatkan tanaman duwet menghasilkan wujud fisik kebudayaan (sistem budaya), yaitu simbol konstitusi (constitutive symbol) dan simbol kognitif (cognitive symbol).

Tanaman duwet dikategorikan sebagai salah satu bentuk simbol konstitusi dalam masyarakat Desa Triwidadi karena berisi pengetahuan tentang keyakinan yang diterima sebagai rangkaian dogmatis dari kepercayaan tradisional. Dalam pikiran masyarakat petani, mereka meyakini akan pengetahuan leluhurnya. Hal ini mereka pahami sebagai salah satu aturan dalam kehidupan sosialnya, dimana tanaman duwet diakui sebagai pembatas lahan milik, pengikat hubungan sosial antar keluarga dan warga, serta terdapat manfaat gizi dan pengobatan tradisional dalam beberapa bagian tanaman duwet yang bisa mereka manfaatkan. Hal ini sesuai dengan pendapat dari Mead dalam Bogdan and Steven (1993) bahwa pikiran (mind) dan kedirian (self) menjadi bagian dari perilaku manusia yaitu bagian dari interaksinya dengan individu-individu lain, sehingga manusia dapat mengenal dunia dan dirinya sendiri, karena tidak ada pikiran yang timbul lepas bebas dari situasi sosial.

Dyson (1989) berpendapat bahwa manusia bertindak bukan atas dasar aturan-aturan, norma, dan lain sebagainya melainkan atas dasar bagaimana mereka memandang sesuatu hal tersebut. Para leluhur masyarakat Desa Triwidadi mengalami proses tersebut. Secara epitimologis, pengetahuan lokal dari pemanfaatan suatu jenis tumbuhan penghasil buah, tidak terlepas dari proses tingkah laku manusia untuk mengingat sekaligus mengelompokkan jenis-jenis tumbuhan yang sering dijumpai atau dimanfaatkan. Oleh para leluhur, tumbuhan hutan telah mampu dikelompokkan sesuai dengan fungsi manfaat yang diperoleh dari lingkungan alamnya. Pemanfaatan buah duwet oleh masyarakat Desa Triwidadi berkaitan erat dengan proses adaptasi para leluhurnya dalam memberanikan diri mengkonsumsi buah duwet secara langsung. Proses ini dikategorikan ke dalam sistem kognitif (cognitive symbol) atau simbol pengetahuan lokal yang berkaitan dengan penjelasan-penjelasan akal sehat, mengenai pemanfaatan buah duwet oleh para leluhur untuk menterjemahkan sesuatu dari luar ke dalam otaknya, untuk dipakai dan difungsikan, sehingga memberikan keyakinan bahwa buah duwet pada awalnya dapat dikonsumsi secara langsung karena tidak berbahaya (tidak beracun); bahwa buah duwet memiliki rasa yang enak dan khas (rasanya 
sedikit manis agak sepat). Oleh karenanya, buah duwet dikategorikan sebagai salah satu simbol kognitif (cognitive symbol).

Dalam interaksi sosial antara manusia dalam sistem sosialnya terhadap proses pemanfaatan buah duwet, terdapat dua simbol interaksi yakni simbol penilaian (evaluative symbol) dan simbol pengungkapan perasaan (expression symbol). Keberadaan tegakan buah duwet dapat digunakan sebagai simbol hak waris atau nilai sosial dalam tatanan struktur sosial masyarakat Desa Triwidadi. Fakta menunjukkan bahwa tidak semua masyarakat memiliki sistem fungsi pewarisan menggunakan habitat tumbuhan. Hal ini hanya berlaku pada segelintir masyarakat, semisal masyarakat Desa Triwidadi ini. Oleh karena itu, tanaman buah duwet memiliki dualisme pilihan yang dapat atau tidak dapat digunakan sebagai nilai kegunaan fungsi pewarisan dalam lingkup masyarakat Jawa secara keseluruhan. Hal ini menunjukkan bahwa buah duwet merupakan bentuk simbol penilaian (evaluative symbol) yang ada di dalam suku Jawa, khususnya pada masyarakat Desa Triwidadi.

Proses pemanfaatan buah duwet sebagai "cemilan harian", ditemukan simbol pengungkapan perasaan (expression symbol) yang dikhususkan bagi kerabat terdekat ataupun penduduk di luar masyarakat desa. Simbol pengungkapan perasaan yang dimaksud adalah pengungkapan perasaan keakraban, kasih sayang dan penghormatan. Para kerabat ataupun tamu yang diberi jamuan "cemilan harian" duwet pun membalas dengan ungkapan perasaan yang sama. Bagi masyarakat Desa Triwidadi bila sehari saja tidak mengemil buah duwet ketika sedang musim panen, serasa ada yang tidak enak/ kurang. Selain itu, makan cemilan duwet itu pun dilakukan bersama-sama dengan karib kerabat sambil bercengkrama; berkumpul dan mengobrol bersama-sama orang tua, anak muda maupun anak-anak kecil, baik di pagi hari, siang hari ataupun di sore hari.

\section{Konstruksi Kearifan Lokal Pemanfaatan Tanaman Duwet}

Sudut pandang konstruksi sosial Berger, menjelaskan budaya masyarakat tercipta dan dipertahankan atau diubah melalui tindakan dan interaksi manusia melalui eksternalisasi, obyektivasi dan internalisasi (Berger \& Lukhman, 1990). Sementara Von Glasersfeld dalam Ungirwalu and Awang (2011), berpendapat bahwa dalam proses konstruksi pengetahuan diperlukan beberapa kemampuan, seperti (1) Kemampuan mengingat dan mengungkapkan kembali pengalaman; (2) Kemampuan membandingkan, mengambil keputusan mengenai persamaan dan perbedaan; dan (3) Kemampuan untuk lebih menyukai pengalaman yang satu daripada yang lain. Kecenderungan pada banyak masyarakat adalah menyenangi pengalaman tertentu yang berkesan, maka muncullah nilai dari pengetahuan yang dibentuk.

Pada konstruksi kearifan lokal pemanfaatan buah duwet oleh masyarakat Desa Triwidadi, ditemukan enam unsur penting yaitu Pertama, sumber daya lokal; Yakni pemanfaatan sumber daya alam (dalam hal ini hutan rakyat) bagi masyarakat Desa Triwidadi terdiri atas manfaat nyata yang terukur (tangible) berupa hasil kayu, hasil non kayu, serta manfaat yang tidak terukur (intangible) berupa pemanfaatan perlindungan lingkungan keragaman genetik, hubungan sosial dalam bermasyarakat, dan lain-lain.

Kedua, pengetahuan lokal; Pola pemanfaatan pada lahan di Desa Triwidadi dapat dikatakan sebagai salah satu bagian dari pola agroforestri yang banyak dijumpai di Indonesia. Sejarah terbentuknya pekarangan, kebun, talun, dan sejenisnya sejak masa penjajahan Belanda merupakan satu bukti sejarah bahwa rakyat telah menanam pohon di sekitar kehidupannya karena dirasakan bahwa pohon tersebut memberi banyak manfaat, baik secara ekonomi maupun demi lingkungan yang sehat (Awang, 2004). Demikian halnya 
dengan masyarakat petani di Desa Triwidadi, mereka tetap menjaga keberadaan pohon duwet di lahannya, karena pohon duwet memiliki fungsi menjaga ketersediaan air di wilayah lingkungan desa mereka, dan menjadi batas wilayah lahan satu sama lain.

Ketiga, nilai lokal; Wujud kebudayaan pengetahuan praktis dari pola kearifan lokal pemanfaatan buah duwet sebagai interaksi simbolis digunakan sebagai pembentukan identitas dan entitas masyarakat Desa Triwidadi, baik terhadap tegakan (kayu), maupun hasil panen berupa buah sebagai "cemilan harian". Bagian penting dari proses etnoekologi pemanfaatan buah duwet adalah menjadikannya buah duwet sebagai "cemilan harian" oleh seluruh masyarakat Desa Triwidadi tanpa mengenal kalangan usia. Buah duwet dapat dinikmati oleh semua warga tanpa terkecuali bahkan telah menjadi budaya bagi mereka untuk mengkonsumsi buah duwet setiap hari pada saat panen.

Keempat, keterampilan lokal; Pada proses pra-panen kaum wanita dewasa menyiapkan segala sesuatu yang diperlukan. Pada proses panen dan pasca panen, kaum pria umumnya lebih banyak terlibat secara fisik dalam pemanenan buah duwet. Hal tersebut dikarenakan sifat buah duwet yang rentan, mudah rusak/busuk bila terjatuh ke tanah. Pemanenan dilakukan dengan memetik buah secara langsung dengan tangan. Pemanjatan dilakukan dengan sangat hati-hati dan pelan agar buah-buah yang telah matang tidak jatuh/rontok. Pada proses pasca panen, kaum wanita melakukan pembersihan buah duwet dan penyiapan buah sebagai makanan/ hidangan cemilan keluarga. Bilamana dijual, kaum perempuan meletakkan buah duwet ke keranjang/bakul besar untuk dipikul oleh kaum laki-laki ke pasar.

Kelima, solidaritas lokal; Etnoekologi tentang teknik pemanfaatan buah duwet melibatkan semua kaum laki-laki dan perempuan, tua dan muda, bahkan anak-anak kecil, yakni adanya kegiatan saling berbagi buah duwet pada saat panen, makan cemilan duwet dilakukan bersama dengan karib kerabat sambil bercengkrama, baik di pagi hari, siang hari ataupun di sore hari. Begitu pula pada saat pra-panen, panen, dan pascapanen.

Keenam, mekanisme pengambilan keputusan lokal; Penentuan aktivitas dalam pemanfatan tanaman duwet diatur secara kesepakatan/musyawarah mufakat oleh setiap anggota rumah tangga petani. Proses dan kearifan secara langsung dari awal tahapan pra-panen, panen, dan pengolahan pasca panen telah melembaga. Pengaturan kegiatan tersebut didominasi oleh kepala keluarga, dengan meminta mufakat dari anggota keluarga yang lain. Kegiatan musyawarah mufakat dalam rumah tangga umumnya dilakukan ketika hendak melakukan pemanenan pohon duwet.

Hal yang perlu dipahami bahwa perubahan akan selalu terjadi, tidak ada yang tetap kecuali perubahan itu sendiri. Demikian halnya dengan perubahan pola kearifan lokal pada masyarakat Desa Triwidadi. Perubahan pola kearifan lokal dipengaruhi oleh dua faktor dominan, yaitu (1) Kualitas dan kuantitas manusianya; dan (2) Sistem pengelolaan dalam bentuk teknologi dan kebijakan pemerintah. Proses dan kearifan secara langsung dari awal tahapan pra-panen, panen, dan pengolahan pasca panen telah melembaga, namun keterlibatan dan follow up antar generasi terhadap proses/tahapan pemanfaatan buah duwet akan menentukan berhasil tidaknya proses transfer pengetahuan etnoekologi. Selanjutnya secara garis besar kualitas dan kuantitas manusia berdasarkan kondisi sosial budaya serta lingkungannya. Masalah-masalah pokok yang akan dijumpai adalah sifat ketergantungan masyarakat petani terhadap sumber daya alamnya. Sifat ketergantungan itu tidak hanya pada lingkungan biogeofisik alam tetapi juga merambat pada ketergantungan sosial, khususnya terhadap pemerintah dan para 
pelaku usaha yakni pedagang dan perusahaan. Konstruksi kearifan lokal yang terjadi pada masyarakat petani di Desa Triwidadi.

\section{KESIMPULAN DAN SARAN}

\section{A. Kesimpulan}

Karakteristik ekologi budaya masyarakat petani Desa Triwidadi mengelola lahan sempit mereka dengan memaksimalkan lahan yang mereka miliki dan berusaha menjaga keberadaaan tanaman duwet, karena tanaman duwet memiliki makna dalam berinteraksi sosial dan pemanfaatan tanaman duwet diposisikan sebagai bagian dari kebudayaan mereka. Namun demikian, karena kebutuhan kayu yang semakin tinggi setiap tahunnya, dikhawatirkan keberadaan tanaman duwet akan mengalami kelangkaan.

\section{B. Saran}

Perlu mengapresiasi kearifanlokal masyarat agar terjaga kelestarian keanekaragaman hayati, dalam hal ini tanaman duwet, dengan memperbaiki sistem pengelolaan pembangunan di sektor kehutanan secara berkelanjutan bersama masyarakat. Beberapa model implementasi kebijakan yang dapat dijadikan rujukan rekomendasi dalam pengelolaan pemanfaatan buah duwet antara lain: Mengintegrasikan kembali prinsip pola kearifan pemanfaatan buah duwet yang berkelanjutan ke dalam setiap proses pendidikan non-formal di dalam komunitasnya dengan peningkatan pola interaksi bagi seluruh anggota keluarga melalui kegiatan produktif pola agroforestri berbasis tanaman duwet; Perlu dilakukan difusi dan inovasi teknologi pemanfaatan tanaman duwet, tidak hanya kayu dan buahnya, tetapi juga bagian lain dari tanaman duwet, seperti biji, daun, dan/atau kulit kayunya, agar memiliki nilai finansial tinggi.

\section{UCAPAN TERIMA KASIH (ACKNOWLEDGEMENT)}

Ucapan terima kasih disampaikan kepada Balai Penelitian dan Pengembangan Teknologi Agroforestry dan Tim Jamblang (Aris Sudomo, Soleh Mulyana, Edi Nurohman, dan Srita Nursuse) atas kesempatan dan kerja samanya sehingga penelitian ini dapat dilaksanakan. Kami juga mengucapkan terima kasih kepada para Widyariset Pusat Pembinaan Pendidikan dan Pelatihan Peneliti Lembaga Ilmu Pengetahuan Indonesia atas pendidikan dan pelatihannya dalam membuat karya tulis ilmiah (KTI) yang diberikan pada saat mengikuti Diklat Jabatan Fungsional Peneliti Tingkat I, khususnya Prof. Dr. Dewa Ketut Sadra Swastika, MS.

\section{DAFTAR PUSTAKA}

Afify, A. E.-M. M., Fayed, S. A., Shalaby, E. A., \& El-Shemy, H. A. (2011). Syzygium cumini (pomposia) active principles exhibit potent anticancer and antioxidant activities. African Journal of Pharmacy and Pharmacology, 5(7), 948-956.

Awang, S. A. (2004). Dekonstruksi sosial forestri. Reposisi masyarakat dan keadilan lingkungan. Yogyakarta: BIGRAF Publishing.

Ayyanar, M., \& Subash-Babu, P. (2012). Syzygium cumini(L.) Skeels: Areview of its phytochemical constituents and traditional uses. Asian Pacific journal of tropical biomedicine, 2(3), 240-246.

Balitbang Pertanian. (2007). Prospek dan arah pengembangan agribisnis tanaman obat. Balitbang Pertanian. Jakarta.

Balitbang Pertanian. (2015). Potensi buah duwet Syzigium cumini (Linn) Skeels sebagai anti oksidan serta manfaat lainnya. Retrieved 23 Agustus, 2015, from http://balitbu. litbang. pertanian.go.id/ind/index.php/beritamainmenu-26/114-inovasi-teknologi/685potensi-buah-tropika-duwet-syzygium-cuminilinn-skeels-sebagai-antioksidan-serta-manfaatlainnya.

Berger, P. L., \& Lukhman, T. (1990). Tafsir sosial atas kenyataan. Jakarta: LP3ES.

Bogdan, R., \& Steven, T. J. (1993). Kualitas: Dasardasar penelitian. (Penerjemahan A. Khozin Afandi). Surabaya: Usaha Nasional. 
Diniyati, D., Achmad, B., \& Santoso, H. B. (2013). Analisis finansial agroforestry sengon di Kabupaten Ciamis (Studi kasus di Desa Ciomas Kecamatan Panjalu). Jurnal Penelitian Agroforestry, 1(1), 13-30.

Dyson, L. P. (1989). Kebudayaan dalam kajian laku. masyarakat kebudayaan dan politik. Surabaya: FISIP Universitas Airlangga.

Helmstädter, A. (2008). Syzygium cumini (L.) SKEELS (Myrtaceae) against diabetes-125 years of research. Die Pharmazie-An International Journal of Pharmaceutical Sciences, 63(2), 91101.

Kusumedi, P., \& Jariyah, N. A. (2010). Analisis finansial pengelolaan agroforestri dengan pola sengon kapulaga di Desa Tirip, Kecamatan Wadaslintang, Kabupaten Wonosobo. Jurnal Penelitian Sosial dan Ekonomi Kehutanan, $7(2)$.

Mulyana, S., \& Sudomo, A. (2015). Persepsi masyarakat dan kelangkaan duwet (Syzygium cumini (L) Skeels di Kabupaten Majalengka. Prosiding Seminar Nasional Agroforestry 2015: Inovasi agroforestry mendukung kemandirian bangsa, Bandung 19 November 2015. Ciamis: Balai Penelitian dan Pengembangan Teknologi Agroforestry bekerja sama dengan Fakultas Pertanian Universitas Padjadjaran, World Agorforestry Center (ICRAF), Fakultas Kehutanan Universitas Winaya Mukti, Masyarakat Agroforestri Indonesia, dan Perum Perhutani.

Nurdiani, N. (2014). Teknik sampling snowball dalam penelitian lapangan. Comtech, 5(2), 1110-1118.

Palmolina, M. (2013). Involusi hutan rakyat (kasus di perbukitan Menoreh Kabupaten Kulon Progo). (Tesis Pascasarjana). Yogyakarta: Universitas Gadjah Mada,
Palmolina, M., \& Sudomo, A. (2015). Pemanfaatan hutan dengan konservasi tanaman penghasil obat jenis jamblang Syzigium cumini (Linn). Prosiding Seminar Nasional Restorasi DAS: Mencari keterapduan di tengah isu perubahan iklim, Surakarta 25 Agustus 2015. Surakarta: Balai Penelitian Teknologi Kehutanan Pengelolaan Daerah Aliran Sungai dan Program Pascasarjana Universitas Sebelas Maret.

Prince, P., \& Venon, M. (1998). Effect of Syzygium in plasma antioxidant on alloxant induced diabetes in rats. Journal of Clinical Biochemistry and Nutrition, 25 (2), 81-86.

Satory, D., \& Komariah, A. (2009). Metodologi penelitian kualitatif. Bandung: Alfabeta.

Spreadley, J. P. (2006). Metode etnografi. (Penerjemah Misbah Zulfa Elizabeth). Yogyakarta: Tiara Wacana Yogya.

Susanto, A., \& Sulasno. (2014). Analisis usaha wanatani di kawasan hutan rakyat Kecamatan Gemarang Kabupaten Madiun. Agritek, 15(1), 57-68.

Ungirwalu, A., \& Awang, S. A. (2011). Konstruksi kearifan lokal etnis Wandamen-Papua dalam pemanfaatan buah hitam (Haplolobus monticola). (Tesis Pascasarjana). Yogyakarta: Universitas Gajah Mada.

Utari, A. D. (2010). Strategi pengelolaan hutan negara berbasis keberhasilan pengelolaan hutan rakyat di Provinsi Daerah Istimewa Yogyakarta. Studi kasus kawasan hutan negara di Kabupaten Gunung Kidul. (Disertasi Pascasarjana). Yogyakarta: Universitas Gadjah Mada. 
